\title{
HIGH $\gamma$ ' SOLVUS NEW GENERATION NICKEL-BASED SUPERALLOYS \\ FOR SINGLE CRYSTAL TURBINE BLADE APPLICATIONS
}

\author{
P. Caron \\ Office National d'Etudes et de Recherches Aérospatiales (ONERA) \\ BP72 - 92322 Châtillon - France
}

\begin{abstract}
$\underline{\text { Abstract }}$
A series of single crystal nickel-based superalloys containing additions of thenium and ruthenium were designed with the aid of time-saving formulae allowing to predict some of their physical characteristics. This alloy design programme succeeded in identifying the new generation single crystal alloy MC-NG suited for gas turbine blade and vane applications. This alloy exhibited a density-corrected high temperature creep strength comparable to that of high-rhenium containing alloys, but with a lower density and no propensity to form deleterious TCP phases.
\end{abstract}

\section{Introduction}

The continuous demand of the gas turbine engine manufacturers for an increasing turbine inlet temperature have pushed the alloy designers to develop nickel-based superalloy chemistries with high rhenium contents for single crystal blade applications. This alloying element was indeed shown to have a strong beneficial effect on the high temperature mechanical properties, especially as the creep strength is concerned. The level of rhenium was typically increascd up to $6 \mathrm{wt}$. \% in the alloys CMSX-10 [1] and René N6 [2].

These so-called third generation alloys however suffer from a number of drawbacks mainly due to their high content of rhenium: a high density, up to $9.1 \mathrm{~g} . \mathrm{cm}^{-3}$, a propensity to form deleterious topologically close packed (TCP) phases during exposures at high temperatures and a propensity to form grain defects during single crystal casting.

We therefore decided to explore the possibility of developing new generation nickel-based superalloys for single crystal turbine blade applications with a tempcrature capability significantly increased as compared to that of MC2 [3] which is considered as the best single crystal superalloy without rhenium. The ultimate target was to attain a creep strength comparable to that of high rhenium containing third generation alloys, but with reduced density and no propensity to form TCP phases.

One of the main idea driving this work was to study alloys containing some amounts of ruthenium substituting partially for rhenium. The density of this refractory element is close to that of molybdenum, therefore approximately one-half of that of rhenium. Moreover, preliminary studies showed that alloys containing both rhenium and ruthenium were less prone to precipitation of TCP phase than alloys containing only rhenium.

\section{Alloy Design}

A series of nickel-based experimental alloys was defined by varying the content of different alloying elements, particularly the refractory elements $\mathrm{Mo}, \mathrm{W}, \mathrm{Re}, \mathrm{Ru}$ and $\mathrm{Ta}$, in order to fulfil several requirements : i) a high $\gamma^{\prime}$ solvus temperature; ii) a high amplitude of $\gamma / \gamma^{\prime}$ mismatch; iii) a density as low as possible; iv) a good phasial stability.

The chemistries of the experimental alloys were defined with the help of time-saving formulae allowing to estimate the values of the $\gamma^{\prime}$ solvus temperature, of the $\gamma / \gamma^{\prime}$ mismatch and of the density. The New PHACOMP method [4] was used in order to avoid the precipitation of TCP phases.

An additional objective was to get an acceptable environmental resistance (hot corrosion and high temperature oxidation) taking into account that the protective coatings usually applied on the blades may crack or spall during service. Additions of $0.1 \mathrm{wt} . \%$ of silicon and $0.1 \mathrm{wt} . \%$ of hafnium were therefore made in all the experimental alloys in order to improve the adherence of the 
Table I Aimed Chemical Compositions of Some Relevant Experimental Alloys Compared to that of Reference Alloys (wt.\%)

\begin{tabular}{cccccccccccc}
\hline Alloy & Ni & Co & Cr & Mo & W & Re & Ru & Al & Ti & Ta & Others \\
\hline MC2 & Bal. & 5 & 8 & 2 & 8 & - & - & 5 & 1.5 & 6 & - \\
MC533 & Bal. & - & 7 & - & 5 & 3 & 3 & 6 & - & 6 & $0.1 \mathrm{Si} ; 0.1 \mathrm{Hf}$ \\
MC534 & Bal. & - & 4 & 4 & 5 & 3 & 4 & 5.8 & - & 6 & $0.1 \mathrm{Si} ; 0.1 \mathrm{Hf}$ \\
MC544 & Bal. & - & 4 & 1 & 5 & 4 & 4 & 6 & 0.5 & 5 & $0.1 \mathrm{Si} ; 0.1 \mathrm{Hf}$ \\
MC645 & Bal. & - & 5 & - & 6 & 4 & 5 & 6 & 0.5 & 5 & $0.1 \mathrm{Si} ; 0.1 \mathrm{Hf}$ \\
MC653 & Bal. & - & 4 & 1 & 6 & 5 & 3 & 5.3 & 1 & 6.2 & $0.1 \mathrm{Si} ; 0.1 \mathrm{Hf}$ \\
CMSX-10M & Bal. & 1.75 & 2 & 0.4 & 5.4 & 6.5 & - & 5.78 & 0.24 & 8.2 & $0.08 \mathrm{Nb}$ \\
René N6 & Bal. & 12.5 & 4.5 & 1.1 & 5.75 & 5.35 & - & 6 & - & 7.5 & $0.15 \mathrm{Hf} 0.05 \mathrm{C} ; 0.004 \mathrm{~B}$ \\
Alloy \#11 & Bal. & 12.65 & 5 & 1.55 & 5.65 & 4.50 & 1.60 & 6 & 0.4 & 6.4 & $0.15 \mathrm{Hf} ; 0.05 \mathrm{C} ; 0.004 \mathrm{~B}$ \\
\hline
\end{tabular}

protective alumina scale formed at high temperature, that would be beneficial to the high temperature oxidation resistance as previously demonstrated for the $\mathrm{AM} 3, \mathrm{AM} 1$ and $\mathrm{MC} 2$ single crystal superalloys [5]. In order to preserve the hot corrosion resistance, only moderate levels of Mo and $\mathrm{Ti}$ were added to the experimental alloys.

More than twenty experimental alloys were thus defined, primarily deriving from $\mathrm{MC} 2$, all containing additions of $\mathrm{Re}$ and some of them containing both $\mathrm{Re}$ and $\mathrm{Ru}$ additions. Small-scale laboratory heats of these alloys were melted in a high vacuum induction furnace and single crystal rods were directionally cast by the withdrawal process using $<001>$ oriented seeds. Two additional reference alloys reproducing the chemistries of the high-rhenium containing alloys CMSX-10M [6] and René N6 [2] and one alloy reproducing the chemistry of the Alloy \#11 designed by General Electric [7] and containing both $\mathrm{Re}$ and $\mathrm{Ru}$ were also cast as single crystals for the sake of comparison.

As it will be shown later in this paper, the best balance of properties were obtained with alloys containing both $\mathrm{Re}$ and $\mathrm{Ru}$ additions. The chemistries of five of these most relevant experimental alloys are compared in Table $I$ to that of the reference alloys. MC544 will be ultimately designated MC-NG.

\section{$\gamma$ solvus temperature}

An important objective fixed for this work was to obtain alloys with a $\gamma^{\prime}$ solvus temperature as high as possible in order to promote a very high creep strength at temperatures above $1100^{\circ} \mathrm{C}$. The creep strength of the $\gamma^{\prime}$-strengthened nickel based superalloys is obviously strongly dependent on the volume fraction of fine $\gamma$ phase precipitates. As typically shown in the case of the AM1 single crystal superalloy [8], the solutioning rate of the $\gamma^{\prime}$ phase is rather low when the temperature increases up to typically $1100^{\circ} \mathrm{C}$, whereas it increases rapidly above this temperature. In the high temperature range, the volume fraction of residual $\gamma^{\prime}$ phase is therefore strongly sensitive to the temperature and it was supposed that increasing significantly the $\gamma^{\prime}$ solvus temperature will allow to keep a higher volume fraction of $\gamma$ phase at elevated temperatures.

The values of the $\gamma$ solvus temperatures of the various alloys were primarily estimated using a formula deduced from a multiple lincar regression analysis of experimental data obtained previously at ONERA on a series of nickel-based superalloys [9]. This analysis was continuously refined as and when new data were acquired along the development work of the new generation single crystal superalloys. This formula is currently :

$\mathrm{T}_{\gamma \text { solvus }}\left({ }^{\circ} \mathrm{C}\right)=1299.315-2.415$ wt.\% Co -6.362 wt.\% $\mathrm{Cr}-2.224$ wt.\% Mo +3.987 wt.\% W 0.958 wt. $\% \mathrm{Re}+2.424$ wt.\% Ru 2.603 wt. $\% \mathrm{Al}-4.943$ wt.\% Ti +3.624 wt.\% Ta.

Figure 1 compares these estimated data to experimental data obtained by thermal analysis using a high temperature dilatometer. The specimens were heated up to the corresponding solutioning temperature determined by preliminary heat treatment studies. The full solutioning heat treatment was performed within the dilatometer furnace. The specimens were then cooled to the room temperature. The heating and cooling rates were $3.6 \mathrm{x}$ $10^{-2}{ }^{\circ} \mathrm{C} . \mathrm{s}^{-1}$. The onset of the $\gamma^{\prime}$ precipitation, evidenced at cooling by a significant contraction of the specimen, was taken as the $\gamma^{\prime}$ solvus temperature. For instance, the estimated value of $1265^{\circ} \mathrm{C}$ for MC2 fitted perfectly the corresponding measured value.

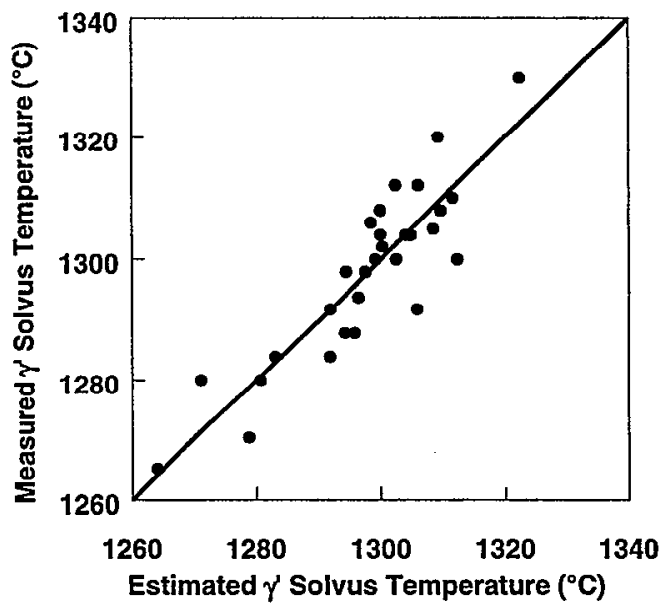

Figure 1: Comparison of estimated and measured values of the $\gamma^{\prime}$ solvus temperature of a series of experimental nickel-based superalloys.

More generally, there was a satisfying agreement between the estimated and experimental values, the largest difference being $14^{\circ} \mathrm{C}$, which corresponds to a relative error of $1 \%$. These results demonstrate the usefulness of such a formula for the prediction of the $\gamma$ solvus temperature knowing the chemistry of the alloy. 
Table II Estimated and Measured Physical Properties

\begin{tabular}{|c|c|c|c|c|c|c|c|c|}
\hline \multirow[t]{2}{*}{ Alloy } & \multicolumn{2}{|c|}{$\gamma^{\prime}$ solvus temperature $\left({ }^{\circ} \mathrm{C}\right)$} & \multicolumn{2}{|c|}{ Density $\left(\mathrm{g} . \mathrm{cm}^{-3}\right)$} & \multirow{2}{*}{$\begin{array}{c}\delta \text { at R.T. } \\
\text { Estimated }\end{array}$} & \multicolumn{2}{|c|}{ New PHACOMP parameters } & \multirow{2}{*}{$\begin{array}{l}\text { Prone to } \\
\text { TCP phase }\end{array}$} \\
\hline & Estimated & Measured & Estimated & Measured & & $\overline{\mathrm{Md}}_{\mathrm{t}}$ & $\overline{\mathrm{Md}_{\gamma}}$ & \\
\hline $\mathrm{MC} 2$ & 1265.1 & 1265 & 8.63 & 8.62 & $0.34 \%$ & 0.987 & 0.918 & - \\
\hline MC533 & 1290.2 & 1292 & 8.638 & 8.64 & $0.21 \%$ & 0.966 & 0.883 & No \\
\hline MC534 & 1304.9 & 1312 & 8.80 & 8.79 & $-0.66 \%$ & 0.980 & 0.924 & Yes \\
\hline MC544 & 1305.3 & 1292 & 8.737 & 8.75 & $-0.24 \%$ & 0.975 & 0.893 & No \\
\hline MC645 & 1308.0 & 1320 & 8.789 & 8.75 & $-0.31 \%$ & 0.977 & 0.903 & No \\
\hline MC653 & 1311.0 & 1308 & 8.928 & 8.93 & $-0.15 \%$ & 0.981 & 0.899 & Yes \\
\hline CMSX-10M & 1322.7 & 1330 & 9.037 & 9.02 & $0.56 \%$ & 0.965 & 0.843 & Yes \\
\hline René N6 & 1278.7 & 1270 & 8.87 & 8.87 & $0.05 \%$ & 0.984 & 0.898 & Yes \\
\hline Alloy \#11 & 1271.4 & 1280 & 8.791 & 8.78 & $-0.48 \%$ & 0.995 & 0.937 & Yes \\
\hline
\end{tabular}

The estimated and experimental values of the $\gamma^{\prime}$ solvus temperature for the alloys of Table I are compared in Table II. The experimental alloys exhibited $\gamma^{\prime}$ solvus temperatures much higher than that of $\mathrm{MC} 2$, that agreed with the initial target. For the experimental alloys of Table I, the increment varied between 27 and $55^{\circ} \mathrm{C}$. It must be pointed out that the highest value was measured for the CMSX-10M alloy, presumably due to the low levels of $\mathrm{Cr}$ and $\mathrm{Co}$ which are $\gamma$ solvus temperature depressant elements and to the high content of $\mathrm{Ta}$ which increases this temperature. On the contrary, the Alloy \#11 and René N6 exhibited quite low values of $\gamma^{\prime}$ solvus temperature owing to their high Co content.

To validate the hypothesis that a dramatic increase of the $\gamma^{\prime}$ solvus temperature would lead to a significant increment of the volume fraction of residual $\gamma^{\prime}$ phase at temperatures higher than $1100^{\circ} \mathrm{C}$, some quantitative measurements were performed on the $\mathrm{MC2}$, MC544 and MC653 alloys. In order to facilitate the $\gamma^{\prime}$ area fraction evaluation, measurements were made on pre-rafted specimens. Interrupted creep tests were thus performed at $1050^{\circ} \mathrm{C}$ on cylindrical specimens of the three alloys. Samples were machined from the specimen gauges, then heat treated in argon for one hour at $1150,1200^{\circ} \mathrm{C}$ and $1250^{\circ} \mathrm{C}$, with salted iced water quenching in order to freeze the high temperature microstructure. Samples for scanning electron microscopy (SEM) were prepared with sections parallel to the $\langle 001\rangle$ tensile axis to obtain side views of the $\gamma / \gamma^{\prime}$ rafted microstructure. Using the back-scattering electron mode allowed to perfectly differentiate the two phases.

Moreover, supposing that the $\gamma^{\prime}$ rafts were infinitely long as compared to their thickness, it was assumed that the area fraction of $\gamma$ phase measured on such a section was close to its volume fraction. Such examples of microstructures observed after a hold at $1200^{\circ} \mathrm{C}$ are illustrated by the micrographs of Figure 2. Curves of Figure 3 show the variation with temperature of the volume fraction of $\gamma^{\prime}$ phase in MC2, MC544 and MC653 alloys. Between $1150^{\circ} \mathrm{C}$ and $1250^{\circ} \mathrm{C}$, the $\gamma^{\prime}$ volume fraction is significantly higher in the new alloys, MC653 showing the highest content of $\gamma^{\prime}$. There is effectively a good correlation between the residual content of $\gamma$ phase and the $\gamma$ solvus temperature.

\section{Density}

When designing the chemistry of the experimental alloys, a particular attention was devoted to the control of the density. An increase of the density will be indeed penalising for the rotating blades and for the disk at which the blades are attached. Particularly, when adding heavy refractory elements such as $\mathrm{Re}$ in the most recently developed alloys, a fraction of the potential creep strength improvement is lost due to the parallel increase of the density. The creep strength advantage offered by the third generation alloys as compared to the older ones is thus reduced when evaluated on a specific strength basis.

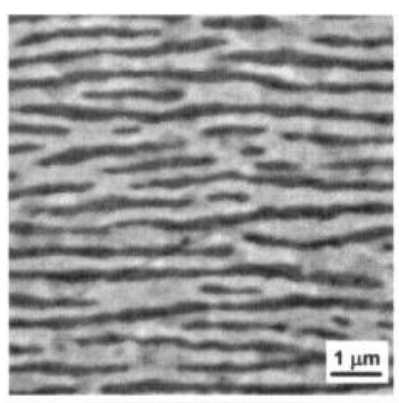

a) $\mathrm{MC} 2, \mathrm{fv}_{\gamma}=32 \%$

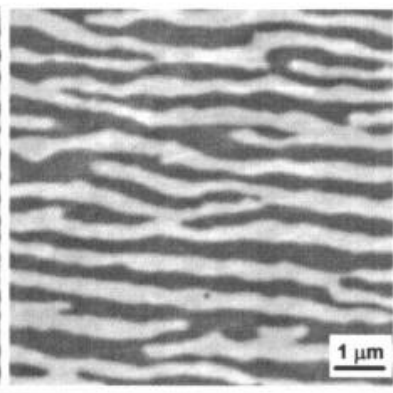

b) $\mathrm{MC} 544, \mathrm{fv}_{\gamma^{\prime}}=47 \%$

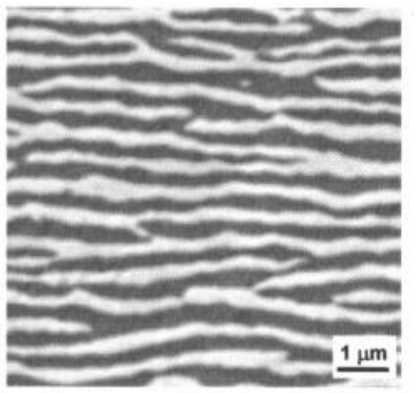

c) $\mathrm{MC} 653, \mathrm{fv}_{\gamma^{\prime}}=53 \%$

Figure 2: $\gamma / \gamma^{\prime}$ microstructures of pre-rafted single crystal alloys after a hold for 1 hour at $1200^{\circ} \mathrm{C}$, followed by iced water quenching (SEM using the back-scattering electron mode : bright phase : $\gamma$, dark phase $: \gamma)$.

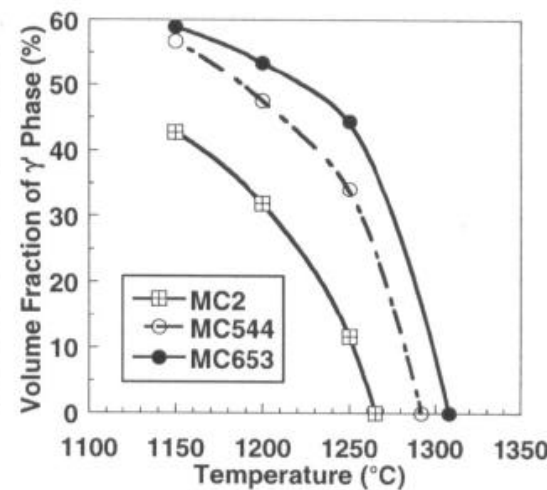

Figure 3: Evolution with temperature of the $\gamma$ volume fraction. The temperatures for nil $\gamma^{\prime}$ phase are the measured $\gamma^{\prime}$ solvus temperatures. 


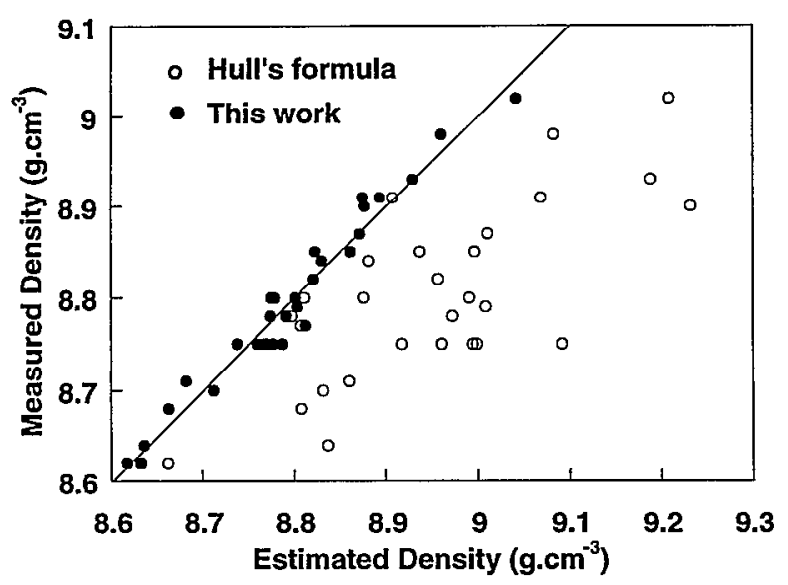

Figure 4: Comparison of estimated and measured values of the density of a series of experimental nickel-based superalloys.

The Hull's formula [10] was primarily applied to predict the density of the experimental alloys from their compositions. This formula contains one term resulting from the application of the rule of mixtures and several additional correction terms deduced from regression analyses performed on data collected on 235 alloys. However, this formula does not contain any correction terms for $\mathrm{Re}$ and $\mathrm{Ru}$. Application of this formula to the whole series of experimental and reference alloys gave the results illustrated in Figure 4. When compared to experimental values calculated from volume and weight measurements, a significant deviation appeared between the estimated and the calculated values, which increased with the density. This therefore showed the necessity to include correction terms related to $\mathrm{Re}$ and $\mathrm{Ru}$ in the Hull's formula.

Instead of trying to modify the Hull's formula, a multiple linear regression analysis of expcrimental data obtaincd on the experimental and reference alloys was run. As for the $\gamma^{\prime}$ solvus temperature evaluation, this analysis was refined continuously along the design procedure of the new alloys and the resulting formula is currently :

d $\left(\right.$ g.cm $\left.{ }^{-3}\right)=8.29604-0.00435$ wt. $\%$ Co -0.0164 wt. $\%$ Cr + 0.01295 wt. $\%$ Mo +0.06274 wt. $\% \mathrm{~W}+0.0593$ wt. $\% \operatorname{Re}+$ 0.01811 wt. $\% \mathrm{Ru}-0.06595$ wt. $\% \mathrm{Al}-0.0236$ wt. $\% \mathrm{Ti}+0.05441$ wt.\% Ta.

The values of the density calculated using this formula for the series of experimental alloys and for the reference alloys are compared in Figure 4 to the corresponding measured values. There was a very good agreement between the predictions and the measurements, the largest relative error being $0.45 \%$. Estimated and measured values for the alloys of Table I are compared in Table II.

\section{$\gamma / \gamma$ mismatch}

A survey of the literature show that the lattice mismatch $\delta=2\left(a_{y}\right.$ $\left.a_{\gamma}\right) /\left(a_{\gamma}+a_{y}\right)$ is generally considered as a factor which could play a significant role on the elevated temperature creep strength of the single crystal superalloys [11-15]. There is however still a debate about the optimum value which must be aimed for improving the high temperature creep behaviour of these alloys [15]. Anyway a common consent scems to be that a large negative value of the mismatch would be preferable because it will promote a fast evolution of the microstructure towards a stable and creep resistant $\gamma / \gamma^{\prime}$ rafted microstructure, and also dense dislocation networks forming at the $\gamma / \gamma^{2}$ interfaces and acting as efficient barriers against mobile dislocations, therefore reducing the creep rate [12-15]. When designing the chemistries of the experimental alloys, we have therefore tried to attain a negative value of the mismatch at high temperature with an amplitude as large as possible in order to optimise this property. We have also aimed to attain various values of mismatch in order to try to evidence some effects of this parameter on the creep behaviour of the experimental alloys.

According to the method used by Watanabe [17], the room temperature (RT) mismatch values of the experimental and reference alloys were calculated from $\gamma$ and $\gamma$ lattice parameters estimated using the following formulas :

$$
\begin{gathered}
a_{\gamma}=a_{N i}+\Sigma V_{i} C_{i} \\
a_{\gamma}=a_{N i 3 N I}+\Sigma V_{i}^{\prime} C_{i}^{\prime}
\end{gathered}
$$

where $a_{\mathrm{Ni}}$ and $\mathrm{a}_{\mathrm{Ni3Al}}$ are the lattice parameters of pure $\mathrm{Ni}$ and pure $\mathrm{Ni}_{3} \mathrm{Al}, \mathrm{V}_{\mathrm{i}}$ and $\mathrm{V}_{\mathrm{i}}^{\prime}$ are the Vegard's coefficients for the element $\mathrm{i}$ in $\mathrm{Ni}$ and $\mathrm{Ni}_{3} \mathrm{Al}$ respectively, and $\mathrm{C}_{\mathrm{i}}$ and $\mathrm{C}_{\mathrm{i}}^{\prime}$ are the atomic fractions of element $i$ in $\gamma$ and $\gamma^{\prime}$ phases.

The lattice parameters for $\mathrm{Ni}$ and $\mathrm{Ni}_{3} \mathrm{Al}$ were taken as $3.524 \AA$ and $3.570 \AA$ respectively [11]. The Vegard's coefficients for $\mathrm{Co}, \mathrm{Cr}$, $\mathrm{Mo}, \mathrm{W}, \mathrm{Al}, \mathrm{Ti}, \mathrm{Ta}$ and $\mathrm{Nb}$ in $\gamma$ and $\gamma^{\prime}$ phases were get from Mishima et al. [18]. As no data existed for Re, we have deduced the Vegard's coefficient of $\mathrm{Re}$ in $\mathrm{Ni}$ from X-ray diffraction experiments performed on Ni-Re solid solutions containing 1at.\% and 2at.\%Re respectively. The resulting value of $V_{R e}$ was 0.441 . The Vegard's coefficient for $\mathrm{Ru}$ in $\mathrm{Ni}$ was taken as 0.3125 [19]. No data were found in the literature for the Vegard's coefficients for $\mathrm{Re}$ and $\mathrm{Ru}$ in $\mathrm{Ni}_{3} \mathrm{Al}$. To calculate these values, we have used the following relationship established by Mishima et al. [18] in the case where the alloying element $i$ substitutes for $\mathrm{Al}$ in $\mathrm{Ni}_{3} \mathrm{Al}$ :

$$
\mathrm{V}_{\mathrm{i}}^{\prime}=\mathrm{V}_{\mathrm{i}}-\mathrm{V}_{\mathrm{Al}}
$$

As atom probe analyses have shown that the refractory elements $\mathrm{Re}, \mathrm{Mo}$ and $\mathrm{W}$ substitute preferentially for $\mathrm{Al}$ in $\mathrm{Ni}_{3} \mathrm{Al}$ [20], we assumed that $\mathrm{Ru}$ exhibited the same behaviour, and applying the equation (3) gave $\mathrm{V}_{\mathrm{Re}}^{\prime}=0.262$ and $\mathrm{V}_{\mathrm{Ru}}^{\prime}=0.1335$.

The following formulae were finally obtained :

$\mathrm{a}_{\mathrm{y}}(\AA)=3.524+0.0196 \mathrm{C}_{\mathrm{co}}+0.110 \mathrm{C}_{\mathrm{Cr}_{\mathrm{r}}}+0.478 \mathrm{C}_{\mathrm{Mo}}+0.444 \mathrm{C}_{\mathrm{W}}$ $+0.441 \mathrm{C}_{\mathrm{Re}}+0.3125 \mathrm{C}_{\mathrm{Ru}}+0.179 \mathrm{C}_{\mathrm{Al}}+0.422 \mathrm{C}_{\mathrm{Ti}}+0.7 \mathrm{C}_{\mathrm{Ta}}+0.7$ $\mathrm{C}_{\mathrm{Nb}}$.

$\mathrm{a}_{\gamma}(\AA)=3.57-0.004 \mathrm{C}_{\mathrm{Cr}_{\mathrm{r}}}^{\prime}+0.208 \mathrm{C}_{\mathrm{M}_{0}}^{\prime}+0.194 \mathrm{C}_{\mathrm{W}}^{\prime}+0.262 \mathrm{C}_{\mathrm{Re}}^{\prime}+$ $0.1335 \mathrm{C}_{\mathrm{Ru}}^{\prime}+0.258 \mathrm{C}_{\mathrm{Ti}}^{\prime}+0.5 \mathrm{C}_{\mathrm{Ta}_{\mathrm{a}}}^{\prime}+0.46 \mathrm{C}_{\mathrm{Nb}}^{\prime}$.

The compositions of the $\gamma$ and $\gamma$ phases were estimated by using a method derived from that developed by Watanabe [17] which itself derived from the PHACOMP method [21]. The values of the calculated lattice mismatch $\delta$ for the relevant experimental alloys and for the reference alloys are compared in Table II. 
Knowing that the thermal expansion coefficient of the $\gamma$ phase in the nickel-based superalloys is less than that of the $\gamma$ phase [13, $22,23]$, a positive mismatch at room temperature will become negative when the temperature will increase above a given value, and a negative mismatch at RT will remain negative with an increasing amplitude [13]. Our method thus allowed to propose a relative ranking of the alloys in respect of the lattice mismatch. For instance, it was foreseen that the alloy MC534 would exhibit a higher amplitude of $\delta$ at high temperature than MC544. It must be pointed out that all the experimental alloys of Table II would exhibit higher amplitude of $\delta$ than $\mathrm{MC} 2$, at the relevant temperatures.

\section{New PHACOMP parameters}

In order to predict and to control the occurrence of deleterious TCP phases during exposure at high temperatures of the experimental alloys, we have applied the New PHACOMP method devised on the basis of the molecular orbital calculations of electronic structures [4]. As done by Yukawa et al. [24,25] and Zhang et al. [26], average values of the Md parameter, $\overrightarrow{M d}_{t}$ and $\overline{\mathrm{Md}}_{\gamma}$, were respectively calculated from the total composition and from the estimated $\gamma$ matrix composition of each experimental and reference alloy using the following formula :

$$
\overline{\mathrm{Md}}=\Sigma \mathrm{C}_{\mathrm{i}}(\mathrm{Md})_{\mathrm{i}}
$$

where $\mathrm{C}_{\mathrm{i}}$ is the atomic fraction of the element $\mathrm{i}$ in the alloy or in the $\gamma$ matrix, and $(\mathrm{Md})_{\mathrm{i}}$ is the $\mathrm{Md}$ value for the element $\mathrm{i}$ reported in Table III.

This method aims at predicting the occurrence of TCP phases such as $\sigma, \mu$ or Laves phases when the Md values become larger than critical values deduced from experience. The values of $\overrightarrow{\mathrm{Md}}_{\mathrm{t}}$ and $\overline{\mathrm{Md}}_{\gamma}$ for the relevant experimental alloys and the reference alloys are reported in Table II.
Table III List of Md Values [4].

\begin{tabular}{ccccc}
\hline Element & Md & & Element & Md \\
\cline { 1 - 2 } \cline { 5 - 5 } $\mathrm{Ti}$ & 2.271 & & $\mathrm{Hf}$ & 3.02 \\
$\mathrm{Cr}$ & 1.142 & & $\mathrm{Ta}$ & 2.224 \\
$\mathrm{Co}$ & 0.777 & & $\mathrm{~W}$ & 1.655 \\
$\mathrm{Ni}$ & 0.717 & & $\mathrm{Re}$ & 1.267 \\
$\mathrm{Nb}$ & 2.117 & & $\mathrm{Al}$ & 1.9 \\
$\mathrm{Mo}$ & 1.55 & & $\mathrm{Si}$ & 1.9 \\
$\mathrm{Ru}^{*}$ & $1.006^{*}$ & & & \\
\hline
\end{tabular}

*Courtesy from Pr. M. Morinaga

\section{Experimental Results}

\section{Microstructures and Heat Treatments}

Some typical as-cast dendritic microstructures of experimental and reference alloys are illustrated in Figure 5. All these alloys contained higher fractions of interdendritic $\gamma / \gamma$ eutectic nodules than observed in first generation single crystal superalloys, and even in second generation single crystal superalloys containing $\mathrm{Re}$ contents close to $3 \mathrm{wt} . \%$. This is mainly due to the higher total level of $\gamma^{\prime}$-former elements such as $\mathrm{Al}, \mathrm{Ti}, \mathrm{Ta}$ and eventually $\mathrm{Nb}$. However, adequate solution heat treatments were identified for the experimental alloys allowing to eliminate all or almost all of the coarse $\gamma^{\prime}$ particles without incipient melting as illustrated in Figure 6. As an example, a two-stage solution heat-treatment including a hold for 3 hours at $1310^{\circ} \mathrm{C}$, then a heating ramp at a rate of $3^{\circ} \mathrm{C} . h^{-1}$ and a final treatment for 3 hours at $1340^{\circ} \mathrm{C}$ led to a complete solutioning of the $\gamma / \gamma^{\prime}$ eutectic and obviously of the secondary $\gamma$ precipitates in the MC544 alloy. All the alloys of Table I have been fully homogenised using such heat treatment procedures. As René N6 and Alloy \#11 contained voluntary additions of carbon some carbide particles remained within the interdendritic areas as shown in Figure 6c.

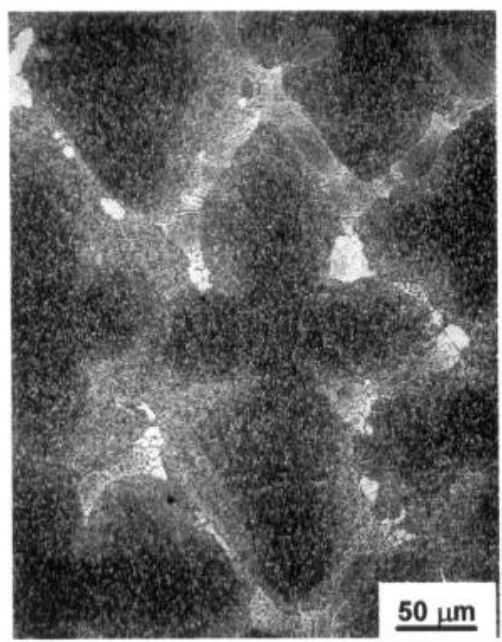

a) $\mathrm{MC} 544$

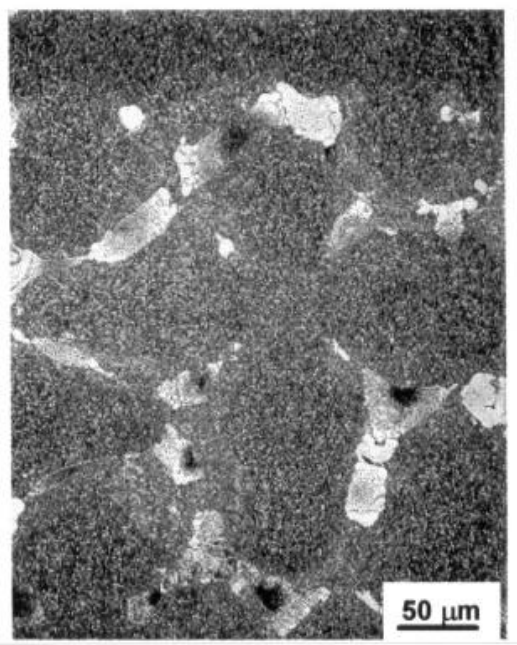

b) MC653

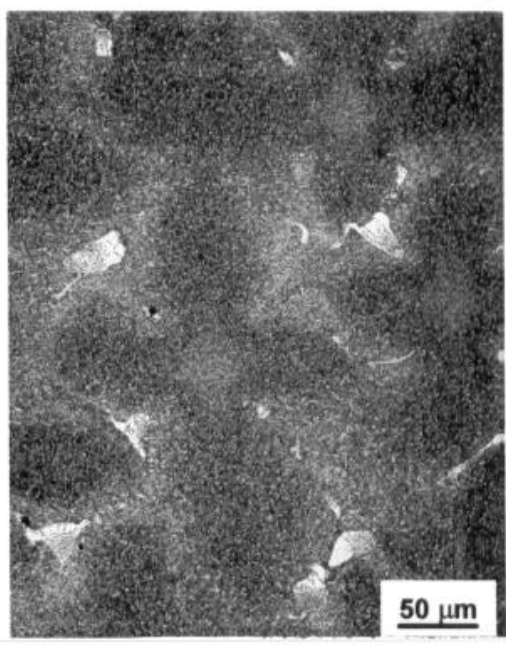

c) Alloy \#11

Figure 5: As-cast dendritic structures of $<001>$ single crystals. 


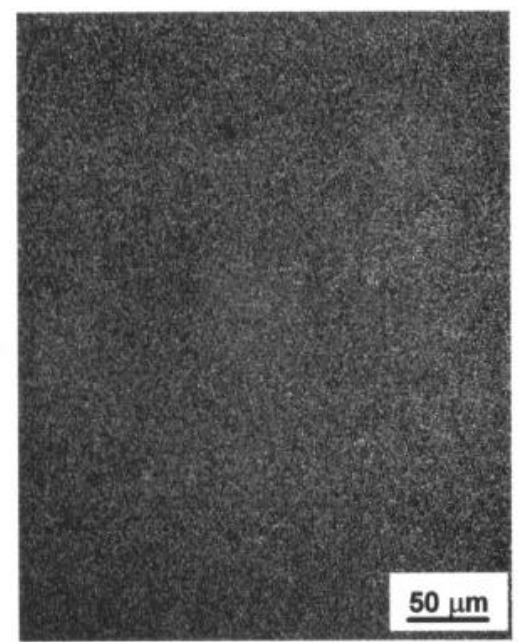

a) $\mathrm{MC5} 44$

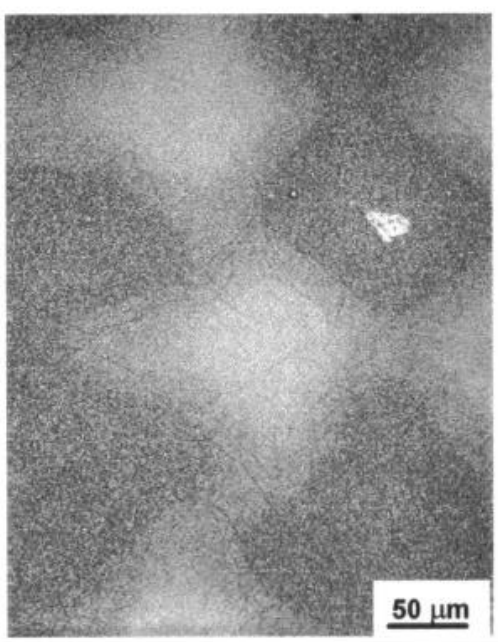

b) MC653

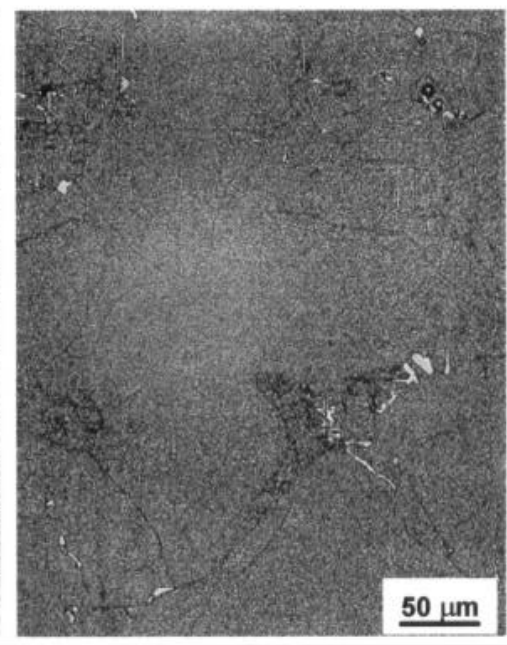

c) Alloy \#11

Figure 6: Solution heat-treated microstructures of $<001>$ single crystals

After complete solutioning, all the experimental alloys were applied an ageing heat treatment for 4 hours at $1100^{\circ} \mathrm{C}$ followed by a treatment for 24 hours at $850^{\circ} \mathrm{C}$ in order to produce a homogeneous distribution of $\gamma^{\prime}$ precipitates. Depending on the alloy chemistry the mean size of the $\gamma^{\prime}$ particles varied within the range $260-400 \mathrm{~nm}$. As shown in Figure 7, the shape of the precipitates depends on the alloy and it was possible to evidence a relationship between this precipitate shape and the value of the estimated room temperature mismatch. These observations agreed with the results of a number of studies showing that the shape of the $\gamma$ precipitates depend strongly on the value of $\delta$ at the ageing temperature $[27,28]$. A transition from sphere to cube occurred when the amplitude of $\delta$ increases. Such an evolution was observed for our experimental alloys, that demonstrates the validity of our predictive method, if we extrapolate the RT $\delta$ values at $1100^{\circ} \mathrm{C}$ following the argument developed previously.

\section{Creep properties}

Constant load tensile creep tests were performed in air in the temperature range $950^{\circ} \mathrm{C}-1150^{\circ} \mathrm{C}$ on cylindrical specimens $(20$ $\mathrm{mm}$ gauge length, $3 \mathrm{~mm}$ diameter) machined from fully heat treated single crystals. Typical stress-rupture lives obtained on the most relevant experimental alloys and on the reference alloys are compared in Table IV. Typical creep curves are reproduced in Figures 8 to 10 .

Table IV Stress-Rupture Lives (in hours)

\begin{tabular}{cccc}
\hline & \multicolumn{3}{c}{ Creep conditions } \\
\cline { 2 - 4 } Alloy & $\begin{array}{c}\mathrm{T}=950^{\circ} \mathrm{C} \\
\sigma=300 \mathrm{MPa}\end{array}$ & $\begin{array}{c}\mathrm{T}=1050^{\circ} \mathrm{C} \\
\sigma=150 \mathrm{MPa}\end{array}$ & $\begin{array}{c}\mathrm{T}=1150^{\circ} \mathrm{C} \\
\sigma=100 \mathrm{MPa}\end{array}$ \\
\hline MC2 & 198 & 485 & 6 \\
MC533 & 298 & 401 & 52 \\
MC534 & 266 & 372 & 60 \\
MC544 & 458 & 486 & 151 \\
MC645 & 404 & 499 & 185 \\
MC653 & 456 & 726 & 194 \\
CMSX-10M & 690 & 637 & 137 \\
René N6 & 531 & 434 & 65 \\
Alloy \#11 & 370 & 466 & 45 \\
\hline
\end{tabular}

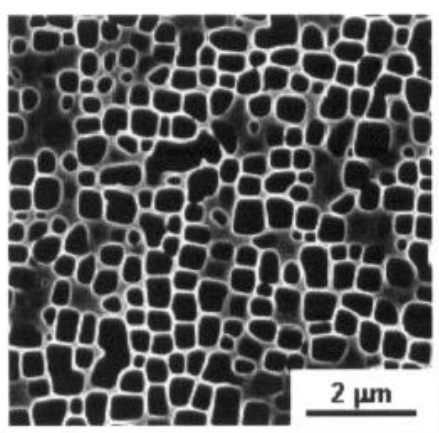

a) $\operatorname{MC} 520 ; \delta_{\text {cal. }}=0.793 \%$

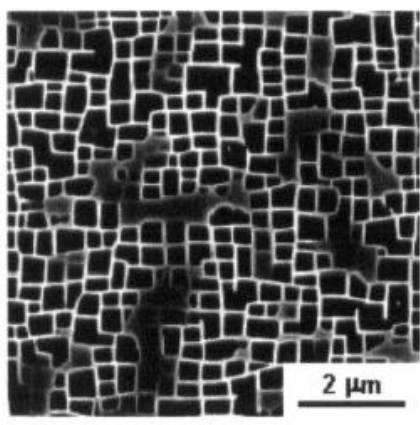

b) $\mathrm{MC} 544 ; \delta_{\text {cal. }}=0.059 \%$

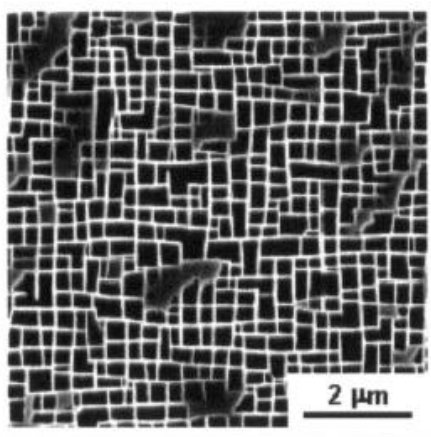

c) $\mathrm{MC} 645 ; \delta_{\text {cal. }}=-0.315 \%$

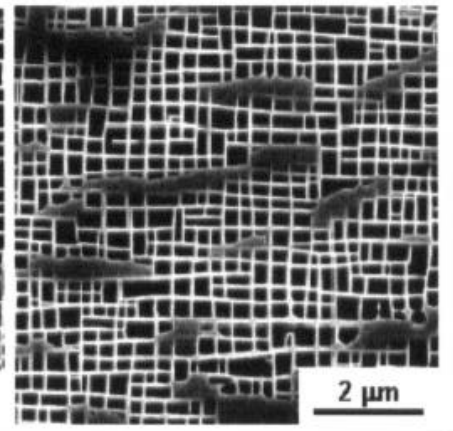

d) $\mathrm{MC534} ; \delta_{\text {cal. }}=-0.665 \%$

Figure 7: Relationship between the RT estimated lattice mismatch $\delta$ and the shape of the $\gamma^{\prime}$ precipitates. 


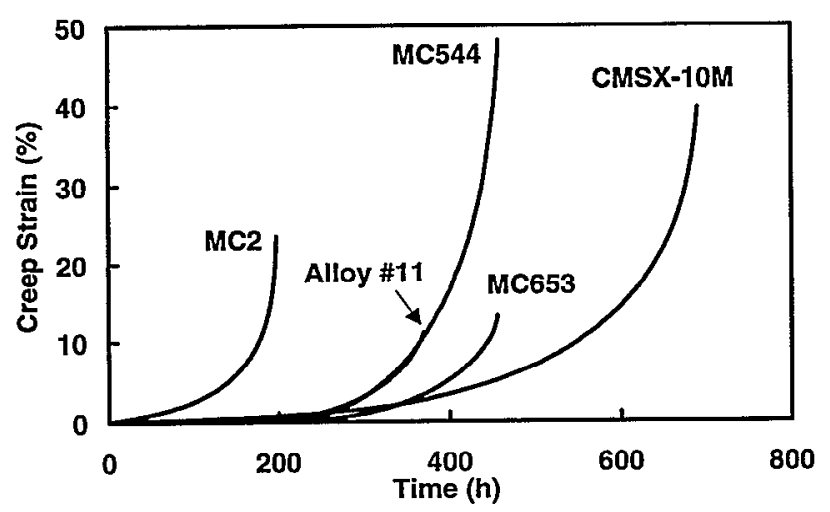

Figure 8: Typical creep curves at $950^{\circ} \mathrm{C}$ and $300 \mathrm{MPa}$.

The studies aiming at understanding in details the effects of chemistry modifications on the creep behaviour of these new alloys are still in progress, but it is already possible to draw some hypotheses to explain the significant differences observed here between the various alloys.

Compared to $\mathrm{MC2}$, all the Re-containing alloys exhibited significantly improved creep lives at $950^{\circ} \mathrm{C}$. This advantage is thought to be due to the addition of Re that slows down all the diffusion-controlled processes which influence the creep behaviour of these alloys [29]. The coarsening rate of the $\gamma$ precipitates is thus strongly reduced, and the mobility of the matrix dislocations which move essentially by a diffusioncontrolled climb process at the $\gamma / \gamma^{\prime}$ interfaces is also decreased. At this temperature, the two most resistant alloys are effectively CMSX-10M and René N6 which contain 6.5 wt.\% Re and 5.35 wt.\% Re respectively. Considering the creep curves, the most striking feature relative to the Re-containing alloys is a very low creep rate during a long period before entering the tertiary creep stage, whereas this stage started practically as soon as the load was applied in the case of MC2 which behaviour is representative of Re-free single crystal superalloys.

At $1050^{\circ} \mathrm{C}$, only the MC653 and CMSX-10M alloys exhibited a significant creep life improvement as compared to $\mathrm{MC} 2$, while the other alloys showed at best a comparable stress-rupture life. These results therefore show that adding $\mathrm{Re}$ is not a panacea when searching at improving the creep strength of single crystal superalloys at every temperature.

The creep behaviour at $1050^{\circ} \mathrm{C}$ of this class of alloys is specific in the sense where the strengthening $\gamma$ precipitates generally experience during the primary creep stage a dramatic evolution towards a $\gamma$ rafted morphology, which remains stable during all the secondary creep stage, before to be destabilised during the tertiary creep. It is therefore obvious that the creep behaviour of these alloys will primarily depend on the more or less quick transition from cube to plate morphology of the $\gamma^{\prime}$ particles, and on the morphological stability of the resulting $\gamma / \gamma^{\prime}$ rafted microstructure, which in turn will depend on parameters such as the $\gamma / \gamma^{\prime}$ mismatch and the bulk diffusion rate.

As shown in Figure 9, the various shapes of the creep curves observed for instance for the MC2, MC544 and CMSX-10M alloys thus suggest significant variations of the $\gamma^{\prime}$ rafting behaviour between these three alloys. Preliminary investigations

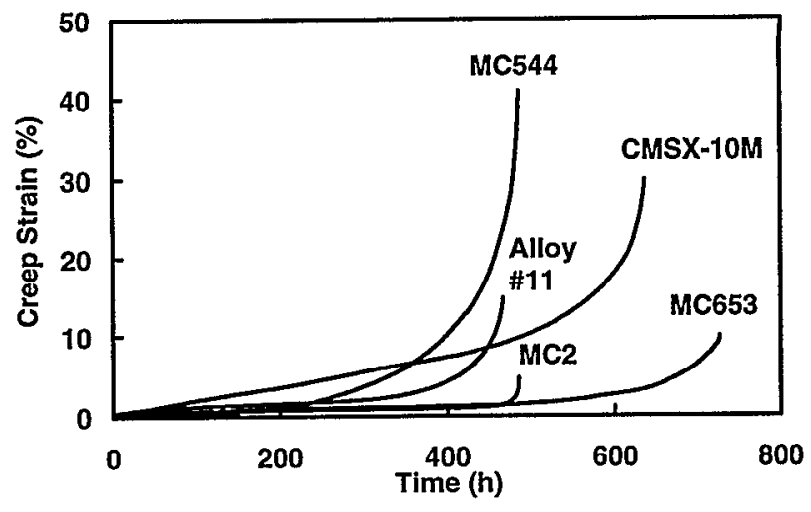

Figure 9: Typical creep curves at $1050^{\circ} \mathrm{C}$ and $150 \mathrm{MPa}$.

of the microstructural variations during creep at $1050^{\circ} \mathrm{C}$ of the MC2 and MC544 alloys have shown that the cube-raft transition is delayed in MC544 compared to $\mathrm{MC2}$, but that the resulting rafted microstructure is less stable in MC544 than in MC2 that correlates with the earlier initiation of the tertiary creep stage [30]. Further investigations are in progress to completely describe and understand the creep behaviour of such alloys at $1050^{\circ} \mathrm{C}$, and with the aim to improve it.

At $1150^{\circ} \mathrm{C}$, the creep strength advantage exhibited by the Recontaining over MC2 was spectacular (Figure 10). Typically, when MC544 is compared to MC2, the creep life is multiplied by a factor of 25 . This dramatic effect is attributed mainly to the larger amount of $\gamma$ phase remaining in the high solvus MC544 and MC653 alloys at this temperature as compared to MC2 (see Figure 3). The Alloy \#11 which exhibitcd a significantly lower creep strength than MC544, MC653 or CMSX-10M, is characterised by a lower $\gamma$ solvus temperature that underlines the importance of this parameter as the very high temperature creep strength is concerned. That obviously does not exclude other beneficial effects resulting from a decrease of the $\gamma^{\prime}$ coarsening kinetic or from solid solution strengthening effects associated to the increase of the refractory element contents. However the increase of the residual fraction of $\gamma$ phase is thought to be the main reason for the very high creep strength at elevated temperatures of the new alloys. That therefore fully justified the initial choice to develop alloys with a high $\gamma^{\prime}$ solvus temperature.

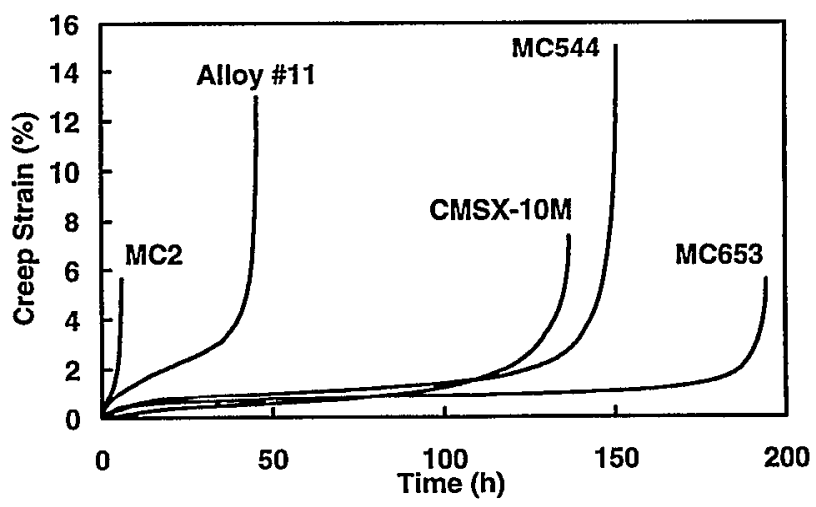

Figure 10: Typical creep curves at $1150^{\circ} \mathrm{C}$ and $100 \mathrm{MPa}$. 


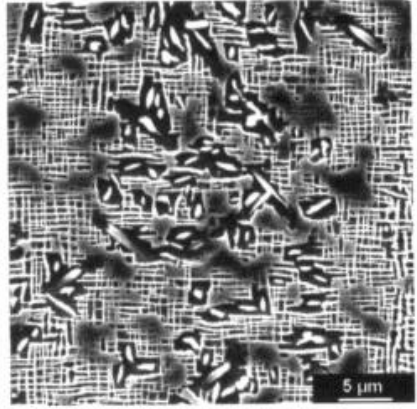

a)

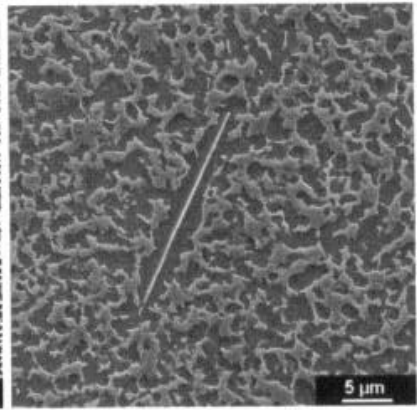

b)
Figure 11: Re-rich TCP phase precipitates in dendrite cores: a) Alloy \#11, $1050^{\circ} \mathrm{C} / 200 \mathrm{~h}$; b) $\mathrm{MC} 653,1100^{\circ} \mathrm{C} / 130 \mathrm{MPa} / 216 \mathrm{~h}$.

\section{Microstructural Stability}

Some ageing heat treatments for 200 hours at 950,1050 and $1150^{\circ} \mathrm{C}$ were performed on homogenised samples of the whole series of experimental alloys and of the Re-containing reference alloys in order to check their phasial stability. Microstructural assessments were also performed on stress-ruptured specimens of all the alloys. Some of the experimental alloys were observed to be prone to the precipitation of needle-like Re-rich particles in the dendrite cores whereas the other ones did not contain TCP phases (Figure 11).

Attempt was made to determine the critical values of $\overline{\mathrm{Md}}_{t}$ and $\overline{\mathrm{Md}}_{\gamma}$ above which TCP phases precipitated. The diagram of Figure 12 summarises the results of the microstructural observations. It appeared in fact impossible to determine unique critical values for the $\overline{\mathrm{Md}}$ parameters. Analysis of all the results showed that in any case the values of $\overline{\mathrm{Md}}_{\mathrm{t}}$ and $\overline{\mathrm{Md}}_{\gamma}$ must not go beyond 0.980 and 0.903 respectively to avoid the precipitation of Re-rich TCP phase particles. These values were therefore considered as maximum allowable values when designing the most relevant of our experimental alloys, i.e. MC544, MC645 and MC653 .

However, it was observed that TCP phases may occur for values of $\overline{\mathrm{Md}}_{\mathrm{t}}$ and $\overline{\mathrm{Md}}_{\gamma}$ as low as 0.965 and 0.843 respectively as in the case of CMSX-10M. A more accurate analysis of the results showed that the critical values of the Md parameters decreased as the Re content increased, but at the contrary increased as the Ru level increased in the alloys.

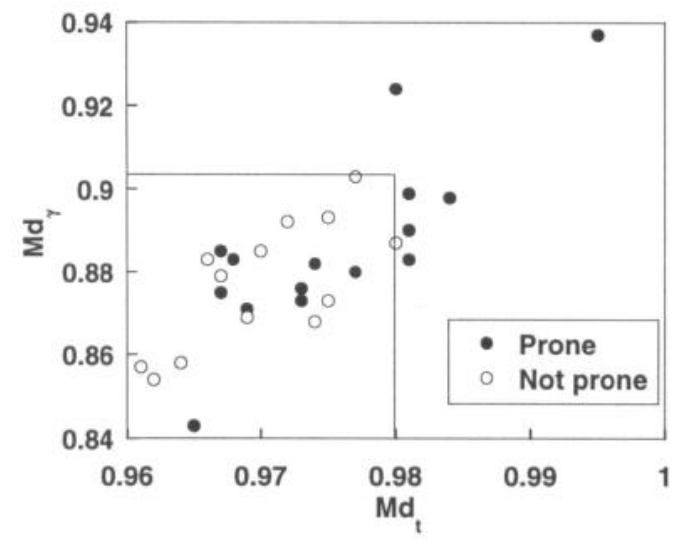

Figure 12: Proneness to TCP phase precipitation in single crystal superalloys as a function of $\overline{\mathrm{Md}}_{t}$ and $\mathrm{Md}_{\gamma}$ parameters.

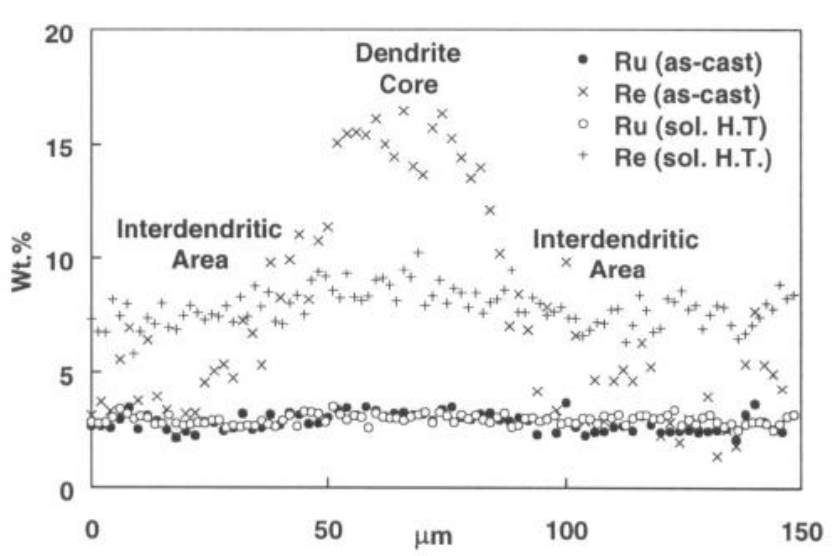

Figure 13: Variations of $\mathrm{Ru}$ and $\mathrm{Re}$ concentrations (wt.\%) throughout dendrites of the MC393 alloy, before and after a solution heat treatment.

The sensitivity of the critical $\overline{\mathrm{Md}}$ values to the Re concentration is due in fact to the residual segregation of this element in the dendrite cores, even after the solution treatment. Figure 13 illustrates the results of electron probe analyses performed through dendrites of the experimental alloy MC393 containing 8.2 wt.\% Re, before and after a homogenisation heat treatment $\left(1330^{\circ} \mathrm{C} / 3 \mathrm{~h}\right.$, ramp at $3^{\circ} \mathrm{C} \cdot \mathrm{h}^{-1}$ up to $1360^{\circ} \mathrm{C}$, then $1360^{\circ} \mathrm{C} / 18 \mathrm{~h} /$ air cooling). These analyses showed that $\mathrm{Re}$ segregated strongly within the dendrite cores during solidification, and that, even after a $31 \mathrm{~h}$ solution heat treatment on this experimental alloy, the $\mathrm{Re}$ concentration may still attain $9.5 \mathrm{wt} \%$ in the dendrite cores. It is this local $\mathrm{Re}$ concentration which would have in fact to be considered when computing the values of the $\overline{\mathrm{Md}}$ values for the prediction of TCP phase precipitation in the dendrite cores. Higher is the $\operatorname{Re}$ content in an alloy, higher will be its concentration within the dendrite cores, even after a long solution heat treatment, and lower will be the critical values for $\mathbf{M d}_{\text {, }}$ and $\overline{\mathrm{Md}}_{\gamma}$.

Another interesting feature evidenced by these analyses is that $\mathrm{Ru}$ did not segregate in the alloy during solidification, that is an advantage compared to Re, because it did not induce local overconcentration. This feature could partly explain why the alloys containing both $\mathrm{Re}$ and $\mathrm{Ru}$ were observed to be less prone to TCP phase precipitation than alloys containing only Re additions. This beneficial effect could be also partly due to a modification of the partitioning ratio of various alloying elements such as molybdenum or rhenium between the $\gamma$ and $\gamma^{\prime}$ phases as suggested by O'Hara et al. [6], that would render the $\gamma$ matrix less prone to the formation of TCP phase particles.

\section{Environmental Resistance}

High temperature cyclic oxidation tests were performed in air at $1100^{\circ} \mathrm{C}$ using one hour-cycles on the experimental alloys. Their performance were comparable to that of $\mathrm{AM} 3, \mathrm{AM} 1$ or $\mathrm{MC} 2$ alloys containing both additions of $\mathrm{Si}$ and $\mathrm{Hf}$. No significant effect of the major alloying elements was evidenced. On the other hand, cyclic hot corrosion tests performed at $850^{\circ} \mathrm{C}$ with addition of $\mathrm{Na}_{2} \mathrm{SO}_{4}$ on some of the experimental alloys and on reference alloys revealed various behaviours depending on the chemistry. Some of these results are illustrated in Figure 14. 


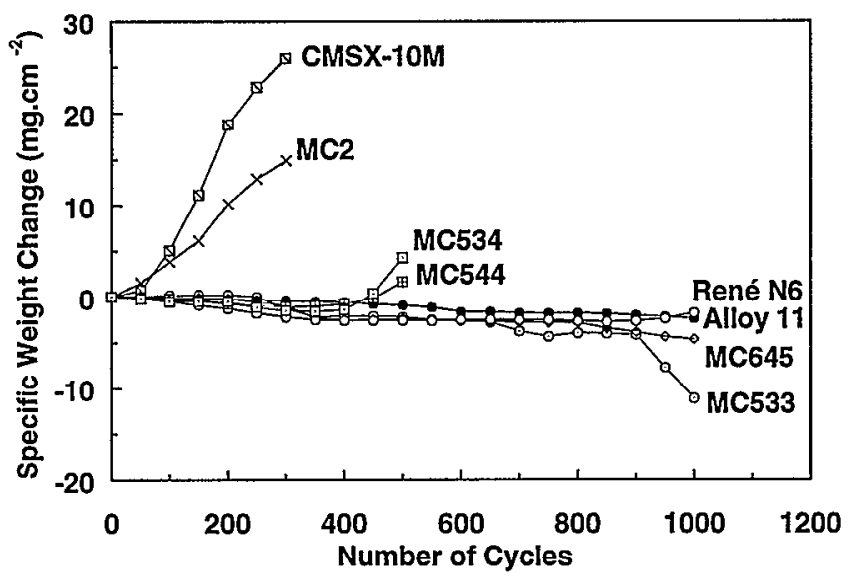

Figure 14: Cyclic corrosion behaviour at $850^{\circ} \mathrm{C}$ of single crystal superalloys.

The experimental alloys all exhibited a hot corrosion resistance superior to that of $\mathrm{MC} 2$ and CMSX-10M. The poor corrosion resistance of $\mathrm{MC} 2$ can be attributed to its rather high level of W and Mo, elements known to be deleterious for this property. It can be pointed out that the most corrosion resistant experimental alloys, MC645 and MC533, are free of Mo. The weak corrosion resistance of CMSX-10M is very likely due to its low level of chromium. It thus appeared that a minimum content of $4 \mathrm{wt} \%$ of chromium must be kept in the alloys in order to ensure an acceptable level of corrosion resistance, even in the case of high rhenium containing alloys. On the other hand, no significant role of the ruthenium was evidenced.

\section{$\underline{\text { Discussion and Conclusions }}$}

Whereas a number of studies have still to be performed to completely understand the effects of chemistry variations on the creep behaviour of the most recently developed single crystal superalloys, it has been shown that, using rather simple hypotheses and with the aid of computation methods aiming at predicting various physical parameters from the alloy chemistry, it was possible to identify promising new generation alloys which offer a unique combination of properties. It was thus demonstrated that the concept of high $\gamma^{\prime}$ solvus alloy was particularly relevant when searching at improving the very high temperature creep strength of these materials. The new PHACOMP method aiming at predicting the occurrence of deleterious TCP phases must be carefully used because it does not take into account the dendritic segregations of low diffusivity elements such as $\operatorname{Re}$ and $\mathrm{W}$. As the lattice parameter mismatch $\delta$ is concerned, its influence on the creep behaviour of the experimental alloys is still not clear, even if the most creep resistant of these alloys are predicted to show a high amplitude of $\delta$ at the tcsting temperatures. As discussed elsewhere [16], the role of the $\gamma / \gamma^{\prime}$ mismatch is complex, particularly at the temperatures where $\gamma^{\prime}$ rafting occurs and further work would have to be performed on this topic to define exactly the optimum value of $\delta$ for given creep conditions.

On a density-corrected basis, the best experimental alloys exhibited a creep strength equivalent to that of the third generation alloys CMSX-10 and René N6 as evidenced by the Larson-Miller plots of Figure 15.

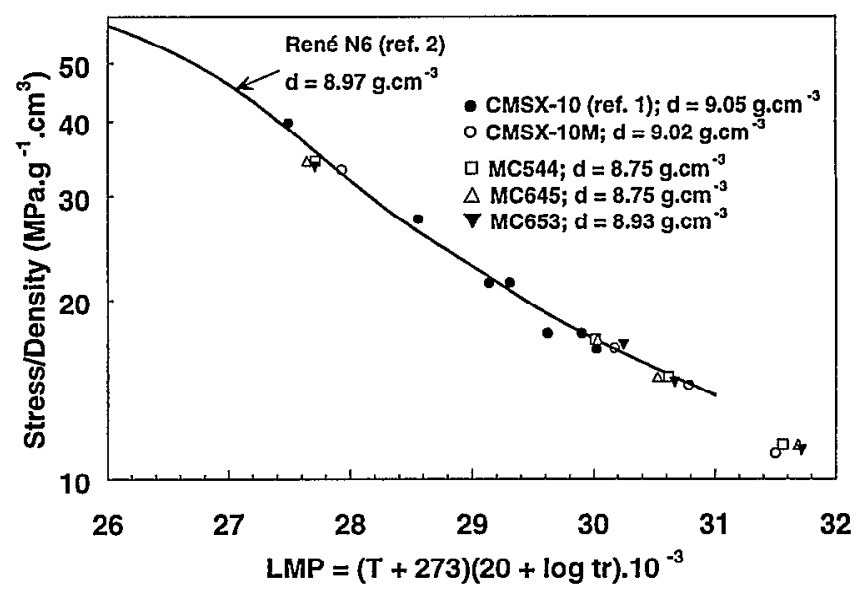

Figure 15: Comparative Larson-Miller stress-rupture data for various single crystal superalloys.

Amongst these various experimental alloys, MC544 exhibited the best balance of overall properties with a density of $8.75 \mathrm{~g} . \mathrm{cm}^{-3}$ and a specific creep strength comparable with that CMSX-10 and René N6, but without any propensity to form rhenium-rich TCP phases. These results demonstrated that it exists a promising alternative to the third generation superalloys for increasing the temperature capability of the single crystal turbine blades without being penalised by an excessive density or by microstructural instability features. Further evaluation of the MC544 alloy under the name of MC-NG is in progress at an industrial scale in order to confirm its interest for various turbine blade and vane applications [31].

\section{Acknowledgements}

This work was funded by the French Ministry of Defence. The author is grateful for the experimental support given by J.-L. Raffestin, S. Navéos, C. Ramusat and F. Passilly.

\section{$\underline{\text { References }}$}

1. G.L. Erickson., "The Development and Application of CMSX-10," Superalloys 1996, ed. R.D. Kissinger et al. (Warrendale, PA: The Minerals, Metals \& Materials Society, 1996), 35-44.

2. W.S. Walston, K.S. O'Hara, E.W. Ross, T.M. Pollock, and W.H. Murphy, "René N6: Third Generation Single Crystal Superalloy," Superalloys 1996, ed. R.D. Kissinger et al. (Warrendale, PA: The Minerals, Metals \& Materials Society, 1996), 27-34.

3. P. Caron, and T. Khan, "Development of a New Nickel Based Single Crystal Turbine Blade Alloy for Very High Temperatures," Advanced Materials and Processes, Vol. 1, ed. H.E. Exner and V. Schumacher (Oberursel, Germany: DGM Informationsgesellschaft $\mathrm{mbH}, 1990), 333-338$.

4. M. Morinaga, N. Yukawa, H. Adachi, and H. Ezaki," New PHACOMP and its Application to Alloy Design", Superalloys 1984, ed. M. Gell et al. (Warrendale, PA: The Metallurgical Society of AIME, 1984), 523-532. 
5. P. Caron, S. Navéos, and T. Khan, "Improvement of the Cyclic Oxidation Behaviour of Uncoated Nickel Based Single Crystal Superalloys," Materials for Advanced Power Engineering 1994 - Part I, ed. D. Coutsouradis et al. (Dordrecht, Holland: Kluwer Academic Publisher, 1994), 1185-1194.

6. G.L. Erickson, Cannon-Muskegon Corporation, US Patent \# $5,540,790$ (1996).

7. O'Hara K.S., Walston W.S., Ross E.W., Darolia R., General Electric Company, US Patent \# 5,482,789 (1996).

8. T. Grosdidier, A. Hazotte, and A. Simon, "Precipitation and Dissolution Processes in $\gamma / \gamma^{\prime}$ Single Crystal Nickel-Based Superalloys," Mat. Sc. and Engin., A256 (1998), 183-196.

9. M. Marty, private communication, ONERA, 1995.

10. F.D. Hull, "Estimating Alloy Densities," Metal Progress, November 1969, 139-140.

11. T.M. Pollock, and A.S. Argon, "Creep resistance of CMSX-3 Nickel Base Superalloy Single Crystal," Acta metall. Mater., 40 (1) (1992), 1-30.

12. R.A. MacKay, and L.J. Ebert, "The Development of $\gamma-\gamma$ ' Lamellar Structures in a Nickel-base Superalloy during Elevated Temperature Mechanical Testing," Mct. Trans. A, 16A (1985), 1969-1982.

13. M.V. Nathal, R.A. MacKay, and R.G. Garlick, "Temperature Dependence of $\gamma-\gamma^{\prime}$ Lattice Mismatch in Nickel-base Superalloys," Mat. Sc. Engin., 75 (1985) 195-205.

14. M.V. Nathal, and R.A. MacKay, "The Stability of Lamellar $\gamma$ $\gamma$ Structures," Mat. Sc. Engin., 85 (1987) 127-138.

15. R.A. MacKay, M.V. Nathal, and D.D. Pearson, "Influence of Molybdenum on the Creep Properties of Nickel-Base Superalloy Single Crystals," Met. Trans. A, 21 A (1990) 381-388.

16. F.R.N. Nabarro, "Rafting in Superalloys," Met. and Mat. Trans. A, 27A (1996) 513-530.

17. R. Watanabe, and T. Kuno, "Alloy Design of Nickel-Base Precipitation Hardened Superalloys," Trans. ISIJ, 16 (1976), 437446.

18. Y. Mishima, S. Ochiai, and T. Suzuki, "Lattice Parameters of $\mathrm{Ni}(\gamma), \mathrm{Ni}_{3} \mathrm{Al}\left(\gamma^{\prime}\right)$ and $\mathrm{Ni}_{3} \mathrm{Ga}\left(\gamma^{\prime}\right)$ Solid Solutions with Additions of Transition and B-subgroup Elements," Acta metall., 33 (6) (1985), 1161-1169.

19. W. Pearson, A Handbook of Lattice Spacings and Structures of Metals and Alloys, Vol. 2 (Oxford, UK: Pergamon Press, 1967), 1135.

20. D. Blavette, P. Caron, and T. Khan, "An Atom-Probe Study of Some Fine-Scale Microstructural Features in Ni-Based Single
Crystal Superalloys," Superalloys 1988, ed. D.N. Duhl et al. (Warrendale, PA: The Metallurgical Society, 1988), 305-314.

21. L.R. Woodyatt, C.T. Sims, and H.J. Beatty, Jr., "Prediction of Sigma-Type Phase Occurrence from Compositions in Austenitic Superalloys", Trans. Met. Soc. AIME, 236 (1966), 519-527.

22. S. Yoshikate, T. Yokokawa, K. Ohno, H. Harada, and M. Yamazaki, "Temperature dependence of $\gamma / \gamma$ ' Parameter Misfit for Nickel-Base Superalloys," Materials for Advanced Power Engineering 1994, Part I, ed. D. Coutsouradis et al. (Dordrecht, Holland: Kluwer Academic Publisher, 1994), 875-882.

23. L. Müller, T. Link, and M. Feller-Kniepmeier, "Temperature Dependence of the Thermal Lattice Mismatch in a Single Crystal Nickel-Base Superalloy Measured by Neutron Diffraction," Scripta Met. et Mat., 26 (1992) 1297-1302.

24. N. Yukawa, M. Morinaga, H. Ezaki, and Y. Murata, "Alloy Design of Superalloys by the d-Electrons Concept," High Temperature Alloys for Gas Turbines and Other Applications 1986 - Part II, ed. W. Betz et al. (Dordrecht, Holland: D. Reidel Publishing Company, 1986), 935-944.

25. N. Yukawa, M. Morinaga, Y. Murata, H. Ezakin, and S. Inoue, "High Performance Single Crystal Superalloys Developed by the d-Electrons Concept," Superalloys 1988, ed. S. Reichman et al. (Warrendale, PA: The Metallurgical Society, Inc., 1988), 225-234).

26. J.S. Zhang, Z.Q. Hu, Y. Murata, M. Morinaga, and N. Yukawa, "Design and Development of Hot Corrosion-Resistant Nickel-Base Single-Crystal Superalloys by the d-Electrons Alloy Design Theory: Part I. Characterisation of the Phase Stability," Met. Trans. A, 24A (1993), 2443-2450.

27. R.A. Ricks, A.J. Porter, and R.C. Ecob, "The Growth of $\gamma$ Precipitates in Nickel-Base Superalloys," Acta. metall., 31 (1983), 43-53.

28. M. Fährmann, P. Fratzl, O. Paris, E. Fährmann, and W.C. Johnson, "Influence of Coherency Stress on Microstructural Evolution in Model Ni-Al-Mo Alloys," Acta. metall. mater., 43 (3) (1995), 1007-1022.

29. A.F. Giamei, and D.L. Anton, "Rhenium Additions to a NiBase Superalloy: Effects on Microstructure," Met. Trans. A, 16A (1985), 1997-2005.

30. P. Caron, M. Benyoucef, A. Coujou, J. Crestou, and N. Clément, "Creep Behaviour at $1050^{\circ} \mathrm{C}$ of a Re-containing Single Crystal superalloy," Paper presented at the International Symposium on Materials Ageing and Life Management (ISOMALM 2000), Kalpakkam, India, 3-6 October 2000.

31. D. Argence, C. Vernault, Y. Desvallées, and D. Fournier, "MC-NG: a $4^{\text {th }}$ Generation Single-Crystal Superalloy for Future Aeronautical Turbine Blades and Vanes", this Conference. 